\title{
A Pilot Randomized Comparative Study of Two Diathermy Power Settings for Monopolar Microdissection and Bipolar Hemostasis during Tonsillectomy
}

\author{
Min-Kwan Baek ${ }^{1}$, Young-Saing Kim², Sung-Ho Choi ${ }^{1}$, \\ Joo-Hyun Woo ${ }^{1}$, Ju-Hyoung Lee ${ }^{1}$, and Dong-Young Kim ${ }^{1}$ \\ ${ }^{1}$ Departments of Otolaryngology-Head and Neck Surgery, ${ }^{2}$ Internal Medicine, Gachon University Gil Hospital, Incheon, Korea
}

편도적출술에서 열전기소작기의 전력량에 따른 술 후 합병증 비교

백민관 ${ }^{1} \cdot$ 김영생 $^{2} \cdot$ 최성호 $^{1} \cdot$ 우주현 $^{1} \cdot$ 이주형 ${ }^{1} \cdot$ 김동영 $^{1}$

가천대학교 길병원 이비인후과, ${ }^{1}$ 내과 ${ }^{2}$

Received July 22,2016

Revised August 31, 2016

Accepted September 12, 2016

Address for correspondence

Dong-Young Kim, MD, PhD

Department of Otolaryngology-

Head and Neck Surgery,

Gachon University

Gil Hospital,

21 Namdong-daero 774beon-gil,

Namdong-gu, Incheon 21565, Korea

Tel $+82-32-460-3762$

Fax $+82-32-467-9044$

E-mail hndyk@gilhospital.com
Background and Objectives Optimal electrical power required for diathermy during tonsillectomy has not been determined. The aim of this pilot study was to evaluate and compare surgical outcomes of using diathermy power settings at 15 watts (W) and $25 \mathrm{~W}$ for monopolar microdissection and bipolar hemostasis during tonsillectomy.

Subjects and Method This prospective, single-center, single-blind, randomized study was conducted on 92 patients who underwent $15 \mathrm{~W}$ or $25 \mathrm{~W}$ monopolar microdissection and bipolar hemostasis for tonsillectomy. Operation times, post-operative pain severities, and rates of hemorrhage were compared between the $15 \mathrm{~W}$ and $25 \mathrm{~W}$ groups.

Results The 92 patients were randomized equally into two study groups. The mean operation duration for the $15 \mathrm{~W}$ group was significantly longer than in the $25 \mathrm{~W}$ group $(18.5 \pm 6.11$ versus $13.4 \pm 6.04$ minutes, $p<0.01$ ). The rate of minimal hemorrhage (defined as an episode of bleeding not significant enough for hospital visitation) for the $15 \mathrm{~W}$ group was significantly higher than for the $25 \mathrm{~W}$ group $(41.3 \%$ versus $20.5 \%, p<0.05)$. No significant intergroup difference was observed between the rates of primary or secondary hemorrhage or postoperative pain scores.

Conclusion Twenty-five watt monopolar microdissection and bipolar hemostasis for tonsillectomy had a shorter mean operation time and a lower post-operative minimal hemorrhage rate than $15 \mathrm{~W}$ monopolar microdissection and bipolar hemostasis.

Korean J Otorhinolaryngol-Head Neck Surg 2016;59(12):836-42

Key Words Diathermy · Hemorrhage $\cdot$ Operative time $\cdot$ Postoperative pain · Tonsillectomy.

\section{Introduction}

Over the past 30 years, an increasing number of tonsillectomies have been performed using "hot" electrosurgical techniques, and diathermy is among the most widely used. ${ }^{1,2)}$ Although diathermal instruments can cut tissues and coagu- late vessels quickly and easily, they can also cause pain and inadvertent injury. ${ }^{3)}$ Some institutions recommend that surgeons use as little diathermy as possible, especially for dissection or hemostasis, ${ }^{4}$ as it is believed increased postoperative pain associated with electrocautery is caused by thermal injuries to surrounding tissues. 
Lowe, et al. ${ }^{5,6)}$ reported the risk of postoperative hemorrhage increases with diathermy power after tonsillectomy by cold steel dissection and bipolar diathermy hemostasis, and that the risk of hemorrhage is high, irrespective of diathermy power settings used during tonsillectomy by diathermal dissection and hemostasis. The use of bipolar diathermy excision can reduce intra-operative blood loss, but inevitably damages adjacent soft tissues to some extent, and this inadvertent injury is likely to increase post-operative pain. On the other hand, monopolar microdissection, which uses a fine diathermy needle, allows sharp dissection at low power levels and reportedly causes less collateral tissue damage.")

The goal of this study was to identify appropriate diathermy power settings for monopolar microdissection/bipolar hemostasis during tonsillectomy. In addition, we conducted a detailed analysis of relationships between diathermy power settings and intraoperative times, rates of hemorrhage, and postoperative pain severities.

\section{Subjects and Method}

\section{Ethical approval and trial design}

This prospective randomized clinical trial was conducted after obtaining approval from the Institutional Review Board
(IRB) of a tertiary hospital (GIRBA2025). The study was designed as single blind control trial. In particular, patients were unaware of the power setting mode used for tonsillectomy.

\section{Surgical indications}

Indications for tonsillectomy included a history of recurrent tonsillitis (i.e., $>6$ severe episodes of tonsillitis during the previous year or $>3$ severe episodes during the previous two consecutive years) or tonsillar hypertrophy (Friedman tonsil size 3 or 4) with obstructive sleep apnea (respiratory disturbance index $>20$ and oxygen saturation $<80 \%$ as determined by polysomnography). Patients aged less than 14 years old and those with a known bleeding disorder, asthma, rheumatic heart disease, unilateral tonsillar hypertrophy, or history of febrile seizures or of peritonsillar abscess were excluded.

\section{Patients}

The initial target number for enrollment was 92. Minimal hemorrhage was defined as any bleeding that stopped spontaneously without requiring a hospital visit. Prior chart review showed some patients that underwent 15 watt (W) or $25 \mathrm{~W}$ monopolar microdissection/bipolar hemostasis complained of minimal hemorrhage ( $45 \%$ and $17 \%$, respectively). Using this data, the sample size of the present study was cal-

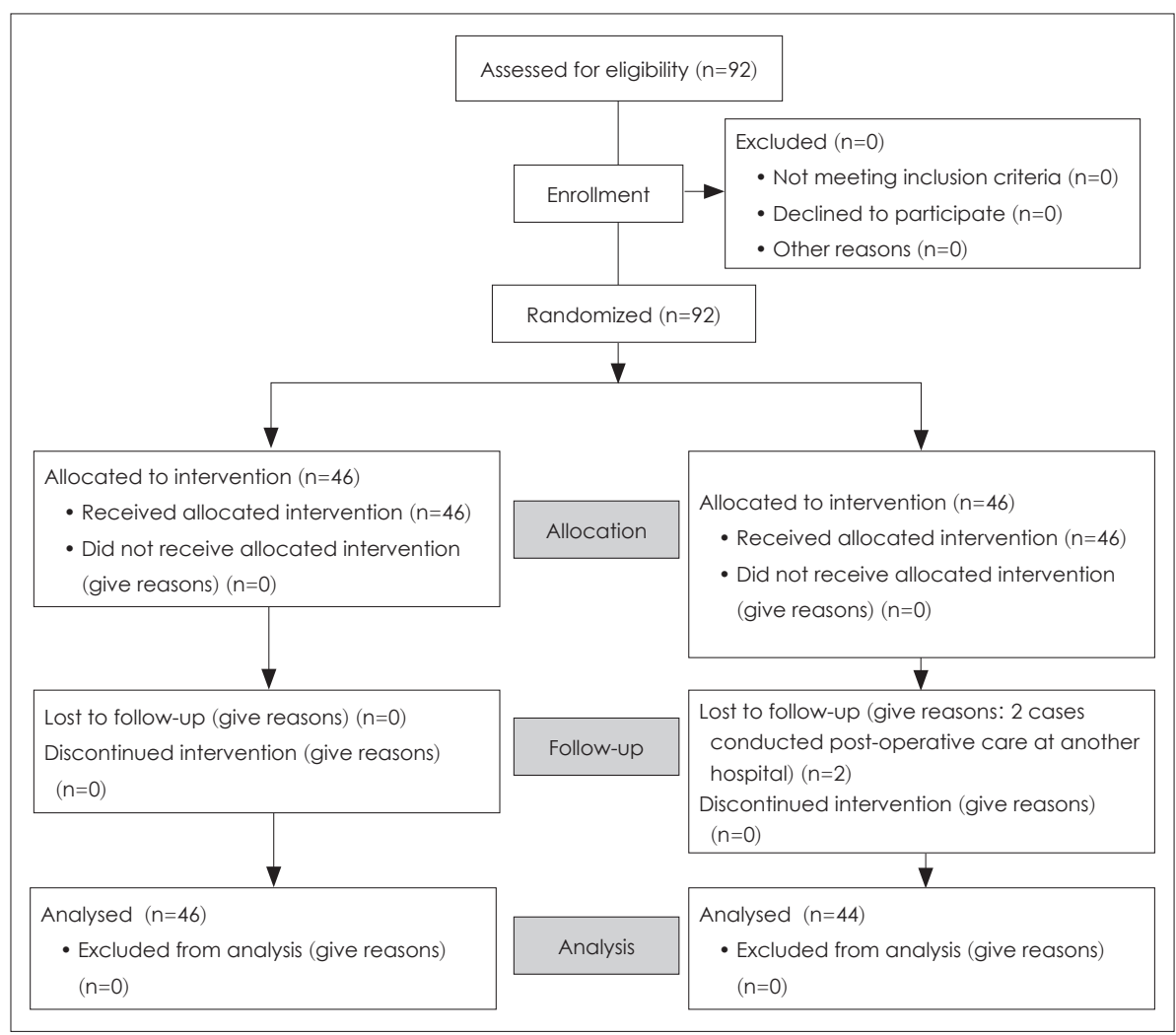

Fig. 1. Flow diagram of the patients participating in the trial. 
culated for a statistical power of $80 \%$ and a significance level of 0.05 . Patients were allocated to the $15 \mathrm{~W}$ or $25 \mathrm{~W}$ monopolar microdissection/bipolar hemostasis groups (15 or $25 \mathrm{~W}$ groups) using randomization blocks (quadruple randomization blocks) and the method detailed on the http://www.randomization.com website. Follow-up data was not available for two patients in the $25 \mathrm{~W}$ group because their post-operative care was undertaken at hospitals closer to their homes (Fig. 1). The 92 study subjects (aged 15 to 40 years) underwent tonsillectomy by an experienced attending single surgeon from April 2011 to December 2013. All agreed to participate in this study after being given a thorough explanation of the procedures involved.

\section{Diathermy power settings}

The 92 patients were equally and randomly allocated to the two study groups. The surgeon recorded power settings used for dissection and hemostasis. In addition, the surgeon used the same type of diathermal instrument (ValleylabTM, Covidien, Minneapolis, MN, USA) in only pure cutting mode of monopolar electrosurgical pencils and bipolar diathermy forceps. The power settings used were chosen to reflect the distribution of power settings commonly used during tonsillectomy; that is, 'low' or 'high' values settings. These values were selected because there was no reason to suppose beforehand that the risk of postoperative morbidity increased with unit power. Values $<25 \mathrm{~W}$ or $>15 \mathrm{~W}$ were considered unrealistic because they would have caused either excessive or insufficient dissection or had a coagulative effect.

\section{Operation and surgical outcomes}

Tonsillectomy by monopolar microdissection/bipolar hemostasis was performed under general anesthesia using oral endotracheal intubation and a McIvor mouth gag. Prophylactic antibiotics were not prescribed. Intraoperative times were recorded from the beginning of tonsillectomy until complete hemostasis had been achieved. Times were recorded in minutes.

Primary hemorrhage was defined as bleeding within 24 hours of surgery, and secondary hemorrhage was defined as bleeding at more than 24 hours after surgery. Minimal hemorrhage was defined as any bleeding that stopped spontaneously without requiring a hospital visit. Patients were asked to record any bleeding event on a daily check list for 2 weeks after surgery. Minimal hemorrhage records were collected and documented at 2-week follow-up visits. Postoperative pain was assessed using a $0-10$ point Visual Analogue Scale (VAS), where 0 indicated "no pain" and 10 indicated "worst imaginable pain". All patients were asked to record pain scores on postoperative days 1, 3, 5, 7, and 14. Patients were discharged on days following surgery in the absence of any severe complication and followed-up one week later in a clinic. At 2-week follow-up visits, postoperative pain score forms were collected and scores were documented. Postoperative complications were also documented. A standardized pain control regimen, that is, $1 \mathrm{mg} / \mathrm{kg}$ of codeine phosphate (maximum dose: 60 $\mathrm{mg}$ ), $15 \mathrm{mg} / \mathrm{kg}$ of acetaminophen (maximum dose: $650 \mathrm{mg}$ ), and $0.2 \mathrm{mg} / \mathrm{kg}$ of ketorolac tromethamine (maximum dose: $10 \mathrm{mg}$ ) every 8 hours by mouth, was used in all 92 patients.

\section{Statistic analysis}

Descriptive statistics are reported as proportions or means with standard deviations. Intergroup differences between intraoperative times and postoperative pain severities were analyzed using the t-test, whereas group hemorrhage rates were analyzed using the chi-square test. Two-sided $p$ values of $<0.05$ were considered statistically significant, and the statistical analysis was performed using SPSS version 20 (SPSS Inc., Chicago, IL, USA).

\section{Results}

The ages of the 92 patients ranged from 15 to 40 years (mean age 24.4 years) and all underwent surgery from April 2011 to December 2013. There were 42 males and 50 females. $15 \mathrm{~W}$ tonsillectomy was performed in 46 cases (the $15 \mathrm{~W}$ group; 23 males, 23 females; mean age: 24.4 years) and $25 \mathrm{~W}$ tonsillectomy in 46 cases (the 25W group; 19 males, 27 females; mean age: 24.4 years). Indications for tonsillectomy were chronic tonsillitis $(77.2 \%, \mathrm{n}=71)$, chronic tonsillitis with obstructive symptoms $(14.1 \%, \mathrm{n}=13)$, and tonsillar hypertrophy with obstructive sleep apnea $(8.7 \%, \mathrm{n}=8) .8$ patients $(8.7 \%)$ were of Friedman grade 4, 27 (29.3\%) grade 3, 34 (37.0\%) grade 2, and $23(25.0 \%)$ grade 1 tonsillar hypertrophy (Table 1$)$.

Mean operation time was $18.5( \pm 6.11)$ minutes in the $15 \mathrm{~W}$ group and $13.4( \pm 6.04)$ minutes in the $25 \mathrm{~W}$ group, and this 5.1 minute difference was highly significant $(p<0.01)$. In the $15 \mathrm{~W}$ group, minimum and maximum operation times were 7 and 32 minutes, respectively, and corresponding values in the $25 \mathrm{~W}$ group were 7 and 38 minutes (Table 2).

In the $15 \mathrm{~W}$ group, no primary postoperative hemorrhage occurred, and in the $25 \mathrm{~W}$ group, one patient $(2.2 \%)$ experienced primary postoperative hemorrhage during the night 
Table 1. Characteristics of patients

\begin{tabular}{|c|c|c|c|c|}
\hline & \multirow{2}{*}{ Total } & \multicolumn{2}{|c|}{ Power setting } & \multirow{2}{*}{ p value } \\
\hline & & $15 W(n=46)$ & $25 W(n=46)$ & \\
\hline Male (\%) & $42(45.7)$ & $23(25.0)$ & $19(20.7)$ & 0.40 \\
\hline Mean age (SD), yrs & $24.4( \pm 6.87)$ & $24.4( \pm 7.39)$ & $24.4( \pm 6.39)$ & 0.96 \\
\hline Tonsil size (\%) & & & & 0.64 \\
\hline Friedman grade 1 & $23(25.0)$ & $10(10.9)$ & $13(14.1)$ & \\
\hline Friedman grade 2 & $34(37.0)$ & $19(20.7)$ & $15(16.3)$ & \\
\hline Friedman grade 3 & $27(29.3)$ & $12(13.0)$ & $15(16.3)$ & \\
\hline Friedman grade 4 & $8(8.7)$ & $5(5.4)$ & $3(3.3)$ & \\
\hline Indication for surgery (\%) & & & & 0.70 \\
\hline Chronic tonsillitis & $71(77.2)$ & $37(40.2)$ & $34(37.0)$ & \\
\hline Chronic tonsillitis with obstructive symptoms & $13(14.1)$ & $6(6.5)$ & $7(7.6)$ & \\
\hline Tonsillar hypertrophy with obstructive sleep apnea & $8(8.7)$ & $3(3.3)$ & $5(5.4)$ & \\
\hline
\end{tabular}

W: watts

Table 2. Intraoperative times for $15 \mathrm{~W}$ and $25 \mathrm{~W}$ monopolar diathermy dissection and bipolar diathermy hemostasis

\begin{tabular}{lccc}
\hline & Range (minutes) & Mean (SD) & p value \\
\hline $15 W(n=46)$ & $7-32$ & $18.5( \pm 6.11)$ & $<0.01$ \\
$25 W(n=46)$ & $7-38$ & $13.4( \pm 6.04)$ & \\
\hline
\end{tabular}

W: watts

Table 3. Rates of primary, secondary, and minimal hemorrhage for $15 \mathrm{~W}$ and $25 \mathrm{~W}$ monopolar diathermy dissection and bipolar diathermy hemostasis

\begin{tabular}{llll}
\hline & \multicolumn{2}{c}{ Power setting } & \\
\cline { 2 - 3 } & $\begin{array}{c}15 \mathrm{~W} \\
(\mathrm{n}=46)\end{array}$ & $\begin{array}{c}25 \mathrm{~W} \\
(\mathrm{n}=44)\end{array}$ & p value \\
\hline Primary hemorrhage* $(\%)$ & $0(0)$ & $1(2.2)$ & 0.16 \\
Secondary hemorrhage $^{\dagger}(\%)$ & $1(2.2)$ & $2(4.5)$ & 0.44 \\
Minimal hemorrhage $^{\ddagger}(\%)$ & $19(41.3)$ & $9(20.5)$ & 0.03 \\
\hline
\end{tabular}

*primary hemorrhage was defined as bleeding within 24 hours of surgery, tsecondary hemorrhage was defined as bleeding beyond 24 hours after surgery, łminimal hemorrhage was defined as any negligible bleeding that stopped spontaneously and did not require a hospital visit. W: watts

following surgery requiring surgical treatment; hemostasis was performed by bipolar diathermy coagulation in an operation room. In the $15 \mathrm{~W}$ group, secondary postoperative hemorrhage occurred in one patient $(2.2 \%)$ on day 7 after surgery requiring blood transfusion and hemostasis by bipolar diathermy coagulation. In the $25 \mathrm{~W}$ group, secondary postoperative hemorrhage occurred in two patients on postoperative days 5 and 7 (incidence 4.5\%). One patient required surgical treatment and bleeding in the other was stopped by gauze compression and the local application of ice in our outpatient clinic. Rates of primary and secondary postoperative hemorrhage were not significantly different in the two groups. Minimal hemorrhage occurred in 19 patients in $15 \mathrm{~W}$ group and in 9 patients in $25 \mathrm{~W}$ group, and thus, the $15 \mathrm{~W}$ group had
Table 4. Postoperative pain scores for $15 \mathrm{~W}$ and $25 \mathrm{~W}$ monopolar diathermy dissection and bipolar diathermy hemostasis at different times after surgery

\begin{tabular}{|c|c|c|c|}
\hline & \multicolumn{2}{|c|}{ Mean $( \pm S D)$} & \multirow{2}{*}{$p$ value } \\
\hline & $15 W(n=46)$ & $25 W(n=44)$ & \\
\hline Postoperative day 1 & $5.17( \pm 2.32)$ & $5.13( \pm 2.25)$ & 0.44 \\
\hline Postoperative day 3 & $5.16( \pm 2.07)$ & $5.41( \pm 1.89)$ & 0.62 \\
\hline Postoperative day 5 & $5.02( \pm 2.53)$ & $4.53( \pm 2.18)$ & 0.36 \\
\hline Postoperative day 7 & $3.88( \pm 2.56)$ & $3.73( \pm 2.13)$ & 0.98 \\
\hline Postoperative day 14 & $1.05( \pm 0.28)$ & $0.81( \pm 0.13)$ & 0.74 \\
\hline
\end{tabular}

W: watts

a significantly higher minimal hemorrhage rate $(p=0.03)$. These minimal hemorrhages stopped spontaneously and did not require a hospital visit (Table 3).

Group pain scores were obtained at 1, 3, 5, 7, and 14 days postoperatively and compared. Pain scores were slightly higher in the $15 \mathrm{~W}$ group on days $1,5,7$, and 14 , but differences were not significant. On the other hand, mean pain score on day 3 was non-significantly higher in the $25 \mathrm{~W}$ group ( $p=0.62$ ) (Table 4). In patient population, the pain scores of patients with chronic tonsillitis on days $1,3,5,7$, and 14 were significantly higher than those with tonsillar hypertrophy regardless of power setting, but these pain score differences were not significant in the $15 \mathrm{~W}$ group (Table 5).

\section{Discussion}

Tonsillectomy is a common surgery in ENT departments, and its major complications are bleeding and pain, and thus, procedural developments tend to target these two complications. Many surgeons try to reduce complications by using anesthesia-based methods, antibiotics, blunt dissection, elec- 
Table 5. Postoperative pain scores for chronic tonsillitis and tonsillar hypertrophy after $15 \mathrm{~W}$ or $25 \mathrm{~W}$ monopolar diathermy dissection and bipolar diathermy hemostasis at different times after surgery

\begin{tabular}{|c|c|c|c|}
\hline \multirow{2}{*}{ Power setting } & \multicolumn{2}{|c|}{ Mean $( \pm S D)$} & \multirow{2}{*}{$p$ value } \\
\hline & Chronic tonsillitis & Tonsillar hypertrophy & \\
\hline \multicolumn{4}{|l|}{ Postoperative day 1} \\
\hline $15 \mathrm{~W}$ & $5.25( \pm 2.35)(n=43)$ & $3.66( \pm 1.15)(n=3)$ & 0.26 \\
\hline $25 \mathrm{~W}$ & $5.38( \pm 2.27)(n=39)$ & $3.20( \pm 0.44)(n=5)$ & $<0.01$ \\
\hline $15 W+25 W$ & $5.32( \pm 2.30)(n=82)$ & $3.37( \pm 0.74)(n=8)$ & $<0.01$ \\
\hline \multicolumn{4}{|l|}{ Postoperative day 3} \\
\hline $15 \mathrm{~W}$ & $5.27( \pm 2.08)(n=43)$ & $3.66( \pm 1.15)(n=3)$ & 0.17 \\
\hline $25 \mathrm{~W}$ & $5.66( \pm 1.84)(n=39)$ & $3.40( \pm 0.89)(n=5)$ & $<0.01$ \\
\hline $15 W+25 W$ & $5.46( \pm 1.97)(n=82)$ & $3.50( \pm 0.92)(n=8)$ & $<0.01$ \\
\hline \multicolumn{4}{|l|}{ Postoperative day 5} \\
\hline $15 \mathrm{~W}$ & $5.16( \pm 2.53)(n=43)$ & $3.00( \pm 1.73)(n=3)$ & 0.12 \\
\hline $25 \mathrm{~W}$ & $4.76( \pm 2.18)(n=39)$ & $2.60( \pm 0.89)(n=5)$ & $<0.05$ \\
\hline $15 W+25 W$ & $4.97( \pm 2.36)(n=82)$ & $2.75( \pm 1.16)(n=8)$ & $<0.01$ \\
\hline \multicolumn{4}{|l|}{ Postoperative day 7} \\
\hline $15 \mathrm{~W}$ & $4.02( \pm 2.56)(n=43)$ & $1.66( \pm 1.15)(n=3)$ & 0.09 \\
\hline $25 \mathrm{~W}$ & $4.00( \pm 2.06)(n=39)$ & $1.60( \pm 1.34)(n=5)$ & $<0.01$ \\
\hline $15 W+25 W$ & $4.01( \pm 2.32)(n=82)$ & $1.62( \pm 1.18)(n=8)$ & $<0.01$ \\
\hline \multicolumn{4}{|l|}{ Postoperative day 14} \\
\hline $15 \mathrm{~W}$ & $1.06( \pm 0.25)(n=43)$ & $0.66( \pm 0.57)(n=3)$ & 0.30 \\
\hline $25 \mathrm{~W}$ & $0.89( \pm 0.30)(n=39)$ & $0.20( \pm 0.44)(n=5)$ & $<0.01$ \\
\hline $15 W+25 W$ & $0.98( \pm 0.29)(n=82)$ & $0.37( \pm 0.51)(n=8)$ & $<0.01$ \\
\hline
\end{tabular}

W: watts

trocautery dissection, or others, and it has been reported blunt dissection and thermal welding dissection are more effective at reducing bleeding and pain than conventional cold dissection. $^{8-11)}$

Many have investigated relations between surgical methods and post-operative bleeding and pain, but in the present study, we set out to determine whether post-operative morbidity depends on the currents used for thermal welding dissection. In addition, several authors have compared postoperative bleeding and pain after 'hot techniques' or explored and compared complications associated with the use of thermal welding instruments, which can significantly reduce operation times as compared with cold dissection. ${ }^{8,9)}$ More recently, studies have been undertaken to identify the most costeffective thermal welding techniques in terms of minimizing complications. Radiofrequency ablation has the advantage of promoting tonsillar fossa wound healing, but post-procedural pain levels are not significantly different from those associated with previously used techniques. Some have reported that the argon laser can reduce operation times and intra-operative blood losses, but no difference in post-operative bleeding or pain was evident when it was compared with other techniques. ${ }^{12,13)}$ Furthermore, it is worth adding that econom- ic factors and efficacy are relevant issues when radiofrequency ablation and argon laser tonsillectomy are compared.

Reducing post-tonsillectomy pain and morbidity while maintaining the speed of surgery constitutes a long-standing challenge. Over the past few years, a number of new devices that reduce thermal injury have been used for tonsillectomy, ${ }^{14)}$ but electrocautery is still widely used because of its ease and speed. ${ }^{15)}$ The heat generated by passage of an electrical current cuts tissues efficiently, but it can injure surrounding tissues, ${ }^{16)}$ although this could be minimized by reducing electrical currents.

In the present study, the cohort consisted of 50 (54.3\%) females and 42 (45.7\%) males, which is similar to previously reported gender distributions, ${ }^{17,18)}$ but not to that reported by Vestergaard, et al. ${ }^{19)}$ in a Danish study, which included pediatric cases. In the present study, patient ages ranged from 15 to 40 years (mean 24.4 years) and pediatric cases were excluded because pain scores and symptom records tend to be unreliable.

Operation times were significantly different in the $15 \mathrm{~W}$ and $25 \mathrm{~W}$ groups. In fact, the time required for $25 \mathrm{~W}$ electrocautery was $28 \%$ shorter. However, a mean difference of 5.1 minutes in operating time is not clinically significant, although 
were this difference applied to longer procedures, meaningfully shorter operation times would be expected. In a study by Izny Hafiz, et al., ${ }^{20)}$ operation times for cold dissection tonsillectomy and coblation tonsillectomy were 14.5 and 8.5 minutes, respectively, but unfortunately start and completion times were not defined, and thus, electrocautery, cold dissection, and coblation tonsillectomy operative times could not be compared.

The use of bipolar diathermy excision has become popular because it reduces intra-operative blood loss. However, all diathermy-based techniques inevitably damage adjacent normal soft tissues. Monopolar dissection using a fine diathermy needle allows sharp dissection and reduces collateral tissue damage, and in one study, it was found the use of a monopolar needle was not associated with additional risk of reactionary or secondary hemorrhage, ${ }^{7)}$ which suggests a combination of monopolar needle dissection and bipolar hemostasis might provide means of reducing intra-operative bleeding and post-operative morbidity. Regarding rates of primary and secondary hemorrhage, no significant difference was observed between our two study groups ( $p=0.16$ and 0.44 , respectively). All 92 study subjects underwent tonsillectomy and no patient experienced a severe postoperative complication; in fact, all were discharged well one day after surgery. Furthermore, the amount of estimated blood loss in both groups was minimal ( $<10 \mathrm{~mL}$; data not shown).

The minimal hemorrhage rate was significantly higher in the $15 \mathrm{~W}$ group than in the $25 \mathrm{~W}$ group. Although bleeding was negligible, bleeding causes patients to feel more uncomfortable during the healing process, and thus, bleeding adversely affects patient satisfaction. However, in the present study, no significant intergroup difference was observed for primary or secondary hemorrhage rates. Calculation of the sample size required for statistical significance based on the results of the present study showed that 337 patients per group would have been required to achieve $80 \%$ power to detect a primary hemorrhage difference between the $15 \mathrm{~W}$ and $25 \mathrm{~W}$ groups at a significance level of 0.05 using the chi-square test, and that 960 patients per group would have been required to detect a significant difference in secondary hemorrhage rates. In the present study, the $15 \mathrm{~W}$ and $25 \mathrm{~W}$ groups contained 46 and 44 patients (two were lost to follow-up) and we only just detected a significant difference in minimal hemorrhage rates $(p=0.03)$.

However, no significant intergroup difference was observed between pain scores, which may have been due to the small sample size, and thus, large-scale study would be needed to confirm the presence of an intergroup difference. Postoperative pain scales showed parallel longitudinal decreases in the two groups. To achieve hemostasis only a minor tissue site was burnt in each patient during bipolar diathermy. Furthermore, slough formation amounts were similar in the two groups. Similar dissection areas from tonsillar fossa and slough formation in the two groups would require similar healing process, and presumably result in similar pain scores. Although the VAS pain scale is statistically meaningful, it is a subjective tool, and thus, we suggest in future studies several pain assessment tests be used, such as, the memorial pain assessment card, the McGill pain Questionnaire, the Brief pain inventory, and others, to reduce individual differences. ${ }^{16,21,22)}$

The limitations of this study are as follows. First, the level of thermal injury in adjacent soft tissue depends on the degree of use of each diathermal instrument. Moreover, because operating mechanisms (either dissection or coagulation) differ for bipolar and monopolar diathermy, operative results are difficult to compare. Second, the running times of diathermal instruments can affect post-operative bleeding and pain. Third, bias may have been introduced because patients might have recorded an instance of 'minimal hemorrhage' or negligible bleeding rather than active bleeding and not visited hospital despite their doctors' recommendations.

In conclusion, degrees of postoperative primary, secondary bleeding, and pain were found to be no different for $15 \mathrm{~W}$ or $25 \mathrm{~W}$ monopolar microdissection and bipolar hemostasis tonsillectomy. However, $25 \mathrm{~W}$ electrocautery tonsillectomy had a significantly shorter mean operation time and a significantly lower minimal hemorrhage rate.

\section{REFERENCES}

1) Murty GE, Watson MG. Diathermy haemostasis at tonsillectomy: current practice-a survey of U.K. otolaryngologists. J Laryngol Otol 1990;104(7):549-52.

2) Walner DL, Parker NP, Miller RP. Past and present instrument use in pediatric adenotonsillectomy. Otolaryngol Head Neck Surg 2007; 137(1):49-53.

3) Celebi S, Yelken K, Celik O, Taskin U, Topak M. Thermal welding vs. cold knife tonsillectomy: a comparison of voice and speech. Int J Pediatr Otorhinolaryngol 2011;75(1):114-7.

4) Shahzad A. Diathermy and tonsillectomy: criticism of NICE. J R Soc Med 2004;97(12):610-1.

5) Lowe D, Cromwell DA, Lewsey JD, Copley LP, Brown P, Yung M, et al. Diathermy power settings as a risk factor for hemorrhage after tonsillectomy. Otolaryngol Head Neck Surg 2009;140(1):23-8.

6) Lowe D, van der Meulen J, Cromwell D, Lewsey J, Copley L, Browne $\mathrm{J}$, et al. Key messages from the National Prospective Tonsillectomy Audit. Laryngoscope 2007;117(4):717-24.

7) Akkielah A, Kalan A, Kenyon GS. Diathermy tonsillectomy: 
comparisons of morbidity following bipolar and monopolar microdissection needle excision. J Laryngol Otol 1997;111(8):735-8.

8) Bukhari MA, Al-Ammar AY. Monopolar electrodissection versus cold dissection tonsillectomy among children. Saudi Med J 2007;28 (10):1525-8.

9) Blanchford H, Lowe D. Cold versus hot tonsillectomy: state of the art and recommendations. ORL J Otorhinolaryngol Relat Spec 2013;75(3):136-41.

10) Gendy S, O’Leary M, Colreavy M, Rowley H, O’Dwyer T, Blayney A. Tonsillectomy--cold dissection vs. hot dissection: a prospective study. Ir Med J 2005;98(10):243-4.

11) Aydin S, Taskin U, Altas B, Erdil M, Senturk T, Celebi S, et al. Posttonsillectomy morbidities: randomised, prospective controlled clinical trial of cold dissection versus thermal welding tonsillectomy. J Laryngol Otol 2014;128(2):163-5.

12) Ferri E, Armato E. Argon plasma coagulation versus cold dissection in pediatric tonsillectomy. Am J Otolaryngol 2011;32(6):459-63.

13) Aksoy F, Ozturan O, Veyseller B, Yildirim YS, Demirhan H. Comparison of radiofrequency and monopolar electrocautery tonsillectomy. J Laryngol Otol 2010;124(2):180-4.

14) Derkay CS, Maddern BR. Innovative techniques for adenotonsillar surgery in children: introduction and commentary. Laryngoscope 2002;112(8 Pt 2 Suppl 100):2.
15) Maddern BR. Electrosurgery for tonsillectomy. Laryngoscope 2002; 112(8 Pt 2 Suppl 100):11-3.

16) Carr MM, Muecke CJ, Sohmer B, Nasser JG, Finley GA. Comparison of postoperative pain: tonsillectomy by blunt dissection or electrocautery dissection. J Otolaryngol 2001;30(1):10-4.

17) Hoddeson EK, Gourin CG. Adult tonsillectomy: current indications and outcomes. Otolaryngol Head Neck Surg 2009;140(1):19-22.

18) Moloney JR, John DG, Jagger C. Age, sex, ethnic origin and tonsillectomy. J Laryngol Otol 1988;102(7):649-51.

19) Vestergaard H, Wohlfahrt J, Westergaard T, Pipper C, Rasmussen $N$, Melbye M. Incidence of tonsillectomy in Denmark, 1980 to 2001. Pediatr Infect Dis J 2007;26(12):1117-21.

20) Izny Hafiz Z, Rosdan S, Mohd Khairi MD. Coblation tonsillectomy versus dissection tonsillectomy: a comparison of intraoperative time, intraoperative blood loss and post-operative pain. Med J Malaysia 2014;69(2):74-8.

21) Vaiman $M$, Gavrieli H. Complex evaluation of pain after tonsillectomy. Acta Otolaryngol. 2007;127(9):957-65.

22) Akural EI, Koivunen PT, Teppo H, Alahuhta SM, Löppönen HJ. Posttonsillectomy pain: a prospective, randomised and double-blinded study to compare an ultrasonically activated scalpel technique with the blunt dissection technique. Anaesthesia 2001;56(11):1045-50. 